\title{
Article \\ Colonic Volume Changes in Paediatric Constipation Compared to Normal Values Measured Using MRI
}

\author{
Hayfa Sharif ${ }^{1,2} \mathbb{D}^{\text {, }}$, Caroline L. Hoad ${ }^{3}$, Nichola Abrehart ${ }^{1}\left(\mathbb{D}\right.$, Penny A. Gowland ${ }^{3}$, Robin C. Spiller ${ }^{1} \mathbb{D}$, \\ Sian Kirkham ${ }^{4}$, Sabarinathan Loganathan ${ }^{4}$, Michalis Papadopoulos ${ }^{4}$, Marc A. Benninga ${ }^{5}$, David Devadason ${ }^{4} \mathbb{D}$ \\ and Luca Marciani $1, *$ (D)
}

check for

updates

Citation: Sharif, H.; Hoad, C.L.; Abrehart, N.; Gowland, P.A.; Spiller, R.C.; Kirkham, S.; Loganathan, S.; Papadopoulos, M.; Benninga, M.A.; Devadason, D.; et al. Colonic Volume Changes in Paediatric Constipation Compared to Normal Values Measured Using MRI. Diagnostics 2021, 11, 974. https://doi.org/ 10.3390/diagnostics11060974

Academic Editor: Keiji Hanada

Received: 23 April 2021

Accepted: 26 May 2021

Published: 28 May 2021

Publisher's Note: MDPI stays neutral with regard to jurisdictional claims in published maps and institutional affiliations.

Copyright: (c) 2021 by the authors. Licensee MDPI, Basel, Switzerland. This article is an open access article distributed under the terms and conditions of the Creative Commons Attribution (CC BY) license (https:/ / creativecommons.org/licenses/by/ $4.0 /)$.
1 Translational Medical Sciences, NIHR Nottingham Biomedical Research Centre at Nottingham University Hospitals NHS Trust, University of Nottingham, Nottingham NG7 2UH, UK;

Hayfa.sharif@nottingham.ac.uk (H.S.); nichola.abrehart@nottingham.ac.uk (N.A.); robin.spiller@nottingham.ac.uk (R.C.S.)

2 Ministry of Health, Civil Service Commission, Amiri Hospital, Kuwait City 15300, Kuwait

3 Sir Peter Mansfield Imaging Centre, School of Physics and Astronomy, University of Nottingham, Nottingham NG7 2RD, UK; caroline.1.hoad@nottingham.ac.uk (C.L.H.); penny.gowland@nottingham.ac.uk (P.A.G.)

4 Nottingham Children's Hospital, Nottingham University Hospitals NHS Trust, Nottingham NG7 2UH, UK; sian.kirkham@nuh.nhs.uk (S.K.); sabarinathan.loganathan@nuh.nhs.uk (S.L.);

Michalis.Papadopoulos@nuh.nhs.uk (M.P.); david.devadason@nuh.nhs.uk (D.D.)

5 Department of Pediatric Gastroenterology, Emma Children's Hospital, Amsterdam UMC, 9, 1105 AZ Amsterdam, The Netherlands; m.a.benninga@amsterdamumc.nl

* Correspondence: luca.marciani@nottingham.ac.uk

Abstract: Background: Functional constipation in children is common. Management of this condition can be challenging and is often based on symptom reports. Increased, objective knowledge of colonic volume changes in constipation compared to health could provide additional information. However, very little data on paediatric colonic volume is available except from methods that are invasive or require unphysiological colonic preparations. Objectives: (1) To measure volumes of the undisturbed colon in children with functional constipation (FC) using magnetic resonance imaging (MRI) and provide initial normal range values for healthy controls, and (2) to investigate possible correlation of colonic volume with whole gut transit time (WGTT). Methods: Total and regional (ascending, transverse, descending, sigmoid, and rectum) colon volumes were measured from MRI images of 35 participants aged 7-18 years (16 with FC and 19 healthy controls), and corrected for body surface area. Linear regression was used to explore the relationship between total colon volume and WGTT. Results: Total colonic volume was significantly higher, with a median (interquartile range) of 309 $\mathrm{mL}$ (243-384 mL) for the FC group than for the healthy controls of $227 \mathrm{~mL}(180-263 \mathrm{~mL})$. The largest increase between patients and controls was in the sigmoid colon-rectum region. In a linear regression model, there was a positive significant correlation between total colonic volume and WGTT ( $R=0.56$, $p=0.0005)$. Conclusions: This initial study shows increased volumes of the colon in children with FC, in a physiological state, without use of any bowel preparation. Increased knowledge of colonic morphology may improve understanding of FC in this age group and help to direct treatment.

Keywords: colon; children; constipation; MRI; volume; transit

\section{Introduction}

Functional constipation (FC) in childhood is common, with a prevalence estimated around $10 \%$ [1]. Constipation can substantially impair quality of life, with marked effects on the child's social functioning [2]. It can result in repeated consultations with specialist consultants, unsuccessful treatment attempts, and the child enduring various investigations. Despite its prevalence, the aetiology of paediatric constipation is still poorly understood [3,4], and diagnosis principally is based on symptom reports alone [5,6]. Increased 
knowledge of colon physiology and morphology could provide healthcare professionals with additional, objective parameters to evaluate.

The length of the colon increases with age from around $1 \mathrm{~m}$ in children aged 4-6 years old [7] to approximately $1.5 \mathrm{~m}$ in adults. The colon is able to accommodate varying volumes of intraluminal contents [8]. It performs the last stage of digestion in the gastrointestinal system, including autonomic motor function, transport and fluid absorption, and storage of waste until defecation. Despite our understanding of the importance of the colon in gastrointestinal pathophysiological processes, relatively little is known about colonic volume in children with FC.

In previous reports, the volume of the adult human colon, either as a whole or divided in anatomical segments, has been estimated using different measurement techniques such as cadaver dissection studies [9,10], perioperative assessment [11], abdominal computed tomography $(\mathrm{CT})$, or barium contrast studies $[12,13]$. However, these techniques are invasive, often require preparation of the colon and use contrast media, which can disturb the physiology, or use ionising radiation, which is particularly undesirable in children.

Recently, studies of the volume of the adult colon have been carried out using magnetic resonance imaging (MRI). The advantages of MRI are excellent soft tissue contrast, cross sectional image quality, speed, and the lack of use of ionising radiation, which can provide comprehensive 3D views of each colonic segment (ascending, transverse, descending colon, and sigmoid-rectum) without preparation or use of contrast agents for the measurement of colonic volume [14-16]. Several studies in adults have demonstrated the responsiveness of the total colonic volume measured by MRI, which, in randomised placebo controlled trials, showed the expected increase in response to bulking agents like psyllium and kiwifruit $[17,18]$. Intraluminal volumes have been measured before and after feeding interventions $[16,18]$ and treatment with bulking agents and laxatives $[17,19]$ to assess the colon volume functional responses. Moreover, MRI can study the colon in a physiological state without the need of bowel preparations to cleanse or distend the organ. Studies in these physiological conditions have reported increased volume of the colon in adults with FC and irritable bowel syndrome (IBS) compared to healthy controls [20,21]. They also showed that colonic volume in healthy subjects decreased by around $1 / 3$ after defecation, indicating that delayed defecation would be predicted to significantly increase total colonic volume $[22,23]$. Delayed defecation with chronic faecal impaction is a common feature of FC in children, but to what extent it would increase colonic volume and correlate with transit has until now been unclear.

Therefore, the primary aim of this study was to measure colonic volume in children with FC and also provide initial normal range values for healthy controls. We used MRI images from a recently published study that measured whole gut transit time (WGTT) [24], which also allowed us to consider possible correlation of the new colonic volume data with WGTT as the secondary aim of this study.

\section{Materials and Methods}

\subsection{Subjects and Study Design}

The data for this retrospective study are from a previous MRI study investigating WGTT [24]. Participants had to be between the ages of 7 and 18 years old. The Rome IV criteria $[5,6]$ were used to identify patients with paediatric FC following a referral either from primary or secondary care into a specialist clinic. Exclusion criteria included gastrointestinal surgery that could affect function, antegrade colonic enema (ACE) patients, inability to lie still for less than 5 mins, and presence of metallic implants or metallic foreign body in the eyes. Healthy controls were recruited from the local population using advertisements. The participants ingested 24 mini-capsule MRI markers each day for 3 days, and were imaged on day 4 and day 7 (a common radiopaque marker protocol) using MRI. The data used here were from the first MRI scan at day 4 . The study was a methods feasibility study and as such, no treatment or lifestyle changes were requested of the participants. Similarly, no questionnaires about defecation were collected. The 
study was approved by the UK National Research Ethics Committee (17/WM/0049) and the UK Medicines and Healthcare Products Regulatory Agency (MHRA) (CI/2017/0054), and was registered on Clinicaltrials.gov (accessed on 1 January 2021) (NCT03564249). All participants below the age of 16 gave written assent to the study and their parent/carer gave informed written consent of participation. All participants between 16 and 18 years old gave informed written consent to the study. The procedure included permission to use the data for further research.

\subsection{Magnetic Resonance Imaging}

All MRI scans were carried out using 3T MRI scanners (Philips, Best, The Netherlands), sited at the Sir Peter Mansfield Imaging Centre at the University of Nottingham. The subjects were not sedated and lay feet first on the scanner bed, in the supine position with a 16-channel abdominal receiver coil wrapped around the abdomen. A short breath-hold multiple-echo (mDIXON) sequence [25] (echo times $1 / 2=1.32 / 2.2 \mathrm{~ms}$, repetition time $=10 \mathrm{~ms}$, flip angle $=20^{\circ}$, field of view $=250 \times 350 \mathrm{~mm}^{2}$, acquired resolution $=1.8 \times 1.8 \times 4.4 \mathrm{~mm}^{3}$ ) was used to acquire both axial and coronal views of the abdomen, divided into short breath-hold (approximately $13 \mathrm{~s}$ ) stacks. The whole MRI procedure took approximately 15 to $20 \mathrm{~min}$. The MRI scans were retrieved and analysed as detailed below.

\subsection{Data Analysis and Statistics}

The coronal mDIXON fat and water in-phase images were used to measure the colonic volume, in keeping with previous work in adults $[16,21,26]$. Individual regional colon volumes were manually segmented on each slice using Medical Image Processing, Analysis, and Visualisation software (MIPAV, NIH, Bethesda). The data analysis was not blinded. The colon of the participants was divided into 4 regions: ascending colon (AC), transverse colon (TC), descending colon (DC), and sigmoid colon and rectum region (SC-R). Regional boundaries commenced at the caecum (ascending) and were fixed in a coronal plane at the superior point of the hepatic flexure (ascending to transverse), at the splenic flexure (transverse to descending) and terminated at the sagittal plane of the commencement of sigmoid colon where the descending colon deviated posteriorly or medially. Each colon region was identified within each coronal image slice, and a region of interest (ROI) drawn around it, building a 3D representation of the morphology from which the volume of each region was measured by summing up the corresponding ROIs and multiplying by slice thickness. If any difficulties were found in visualising the anatomy, axial views were also used to aid navigation. The colon volume data were corrected for body surface area (BSA) using the Mosteller formula [26,27]. The formula calculates BSA as the square root of (height $(\mathrm{cm}) \times$ weight $(\mathrm{kg}) / 3600)$. Linear regression was used to explore the relationship between total colon volume from this study and the individual participants' WGTT values from [24].

Statistical analysis was carried out using Prism 8 (GraphPad Software Inc., La Jolla, CA, USA). Normality of the data was checked using the Shapiro-Wilk normality test. Depending on normality, comparisons between groups were performed using two-tailed $t$-test or Mann-Whitney rank sum test for unpaired data. Differences were considered significant at $p<0.05$.

\section{Results}

Nineteen healthy volunteers with no history of gastrointestinal disease (8 male; 11 female; age $16 \pm 2$ years old; body mass index (BMI) $25 \pm 5 \mathrm{~kg} / \mathrm{m}^{2}$ ) and 16 patients with functional constipation (7 male; 9 female; age $11 \pm 3$ years old; BMI $25 \pm 9 \mathrm{~kg} / \mathrm{m}^{2}$ ) participated in the study. The difference in age between groups was statistically significant (Mann-Whitney test, $p<0.0001$ ). Good-quality images of the colon were obtained in the majority of the 35 participants. The images from 4 participants displayed some breathing artefacts. This, however, did not prevent identification and mapping of the colon. All data from the 35 participants were included in the image analysis. There was a moderate 
positive linear correlation of colon volume with height $(R=0.49$ for patients, $p=0.058$; and $R=0.60$ for controls, $p=0.0068)$ and weight $(R=0.45$ for patients, $p=0.0802$; and $R=0.30$ for controls, $p=0.2163$ ). Moreover, the height and weight of the young participants varied markedly, with some being nearly twice as tall (range $105 \mathrm{~cm}$ to $185 \mathrm{~cm}$ ) and/or 4 times heavier (range $22 \mathrm{~kg}$ to $106 \mathrm{~kg}$ ) than others, which underpinned the use of the colonic volume correction for body surface area.

Example colon reconstructions are shown in Figure 1. A 13-year-old patient with FC with a BMI of $17.7 \mathrm{~kg} / \mathrm{m}^{2}$ had the largest total colon volume in the patient group $(712 \mathrm{~mL})$, with a WGTT of $140 \mathrm{~h}$. This patient presented with a megarectum (Figure 1a), with a sigmoid colon and rectum volume of $243 \mathrm{~mL}$. By comparison, Figure $1 \mathrm{~b}$ shows the colon reconstruction for a 17-year old-healthy control with a BMI of $23.4 \mathrm{~kg} / \mathrm{m}^{2}$ who had the largest colon volume $(360 \mathrm{~mL})$ among the control group and a WGTT of only $16 \mathrm{~h}$. This control participant was one of the tallest ones, with a height of $185 \mathrm{~cm}$.

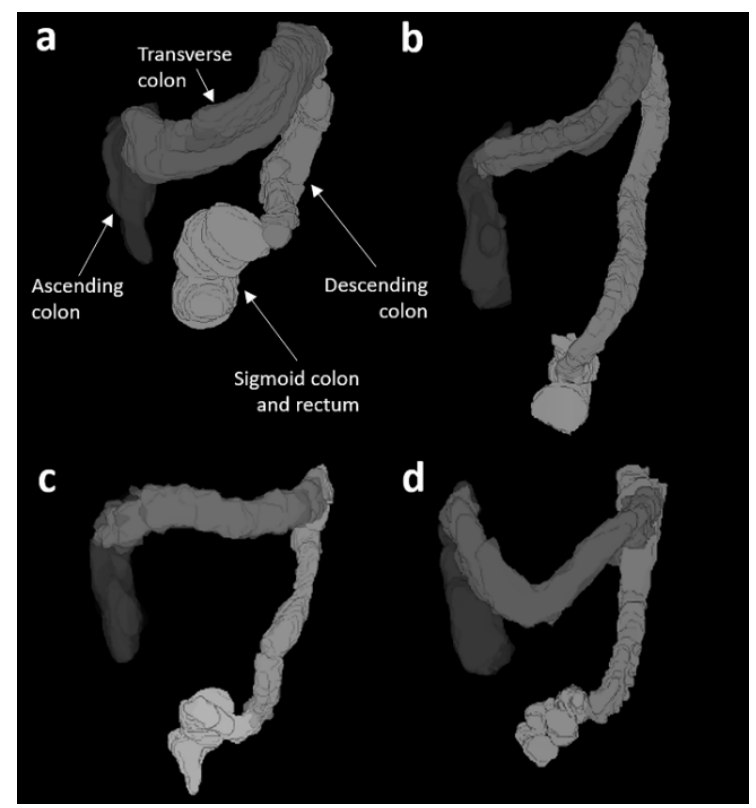

Figure 1. 3D representations of the colon morphology from four different participants whose characteristics were: (a) patient, 13 years old, weight $42 \mathrm{~kg}$, height $154 \mathrm{~cm}, \mathrm{BMI} 17.7 \mathrm{~kg} / \mathrm{m}^{2}$, total colon volume $(\mathrm{TCV})=712 \mathrm{~mL}$, whole gut transit time $(\mathrm{WGTT})=140 \mathrm{hs}$; $(\mathbf{b})$ healthy control, 17 years old, weight $80 \mathrm{~kg}$, height $185 \mathrm{~cm}, \mathrm{BMI}=23.4 \mathrm{~kg} / \mathrm{m}^{2}, \mathrm{TCV}=360 \mathrm{~mL}, \mathrm{WGTT}=16 \mathrm{hs}$; (c) patient, 9 years old, weight $48 \mathrm{~kg}$, height $130 \mathrm{~cm}, \mathrm{BMI} 21.4 \mathrm{~kg} / \mathrm{m}^{2}, \mathrm{TCV}=237 \mathrm{~mL}$, WGTT = $75 \mathrm{hs}$; (d) healthy control, 10 years old, weight $42 \mathrm{~kg}$, height $145 \mathrm{~cm}, \mathrm{BMI}=19.9 \mathrm{~kg} / \mathrm{m}^{2}, \mathrm{TCV}=227 \mathrm{~mL}$, WGTT $=26 \mathrm{hs}$.

The uncorrected colonic volume had some degree of correlation with participants' height (Spearman's $r=0.31, p<0.1$ ) and with participants' weight (between colonic volume and weight (Spearman's $r=0.38, p<0.05$ ).

The total colonic volume corrected for BSA (Figure 2) was $309 \mathrm{~mL}$ (243-384 mL) median (interquartile range) for the young patients with constipation, significantly larger than that for the healthy controls' $227 \mathrm{~mL}(180-263 \mathrm{~mL})(p=0.0081$ Mann-Whitney twotailed test). The data showed that $63 \%$ of patients had a colonic volume above the $75 \%$ centile of normal control values, and $25 \%$ of patients had the colon volume above the 95 th centile (upper limit of normal) of the healthy control values. 


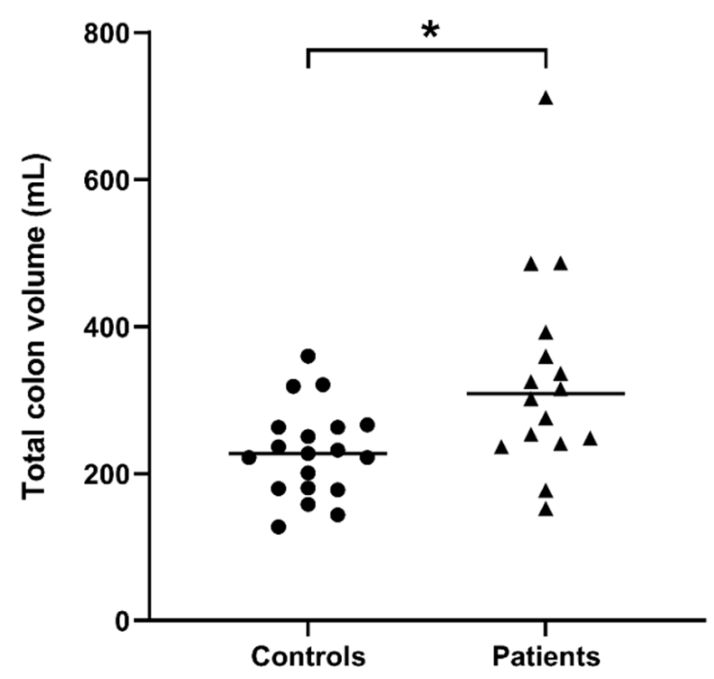

Figure 2. Total colon volume corrected for both body surface area of $n=19$ controls and $n=16$ patients with constipation. The horizontal lines indicate the median, ${ }^{*} p=0.0081$ two-tailed Mann-Whitney test.

The regional colon volumes presented in Figure 3 showed that the larger increase between controls and patients was in the SCR-region ( $p=0.0410$, Mann-Whitney onetailed test), with 9 constipated patients having SCR-volume above the $95 \%$ CI of the control values.

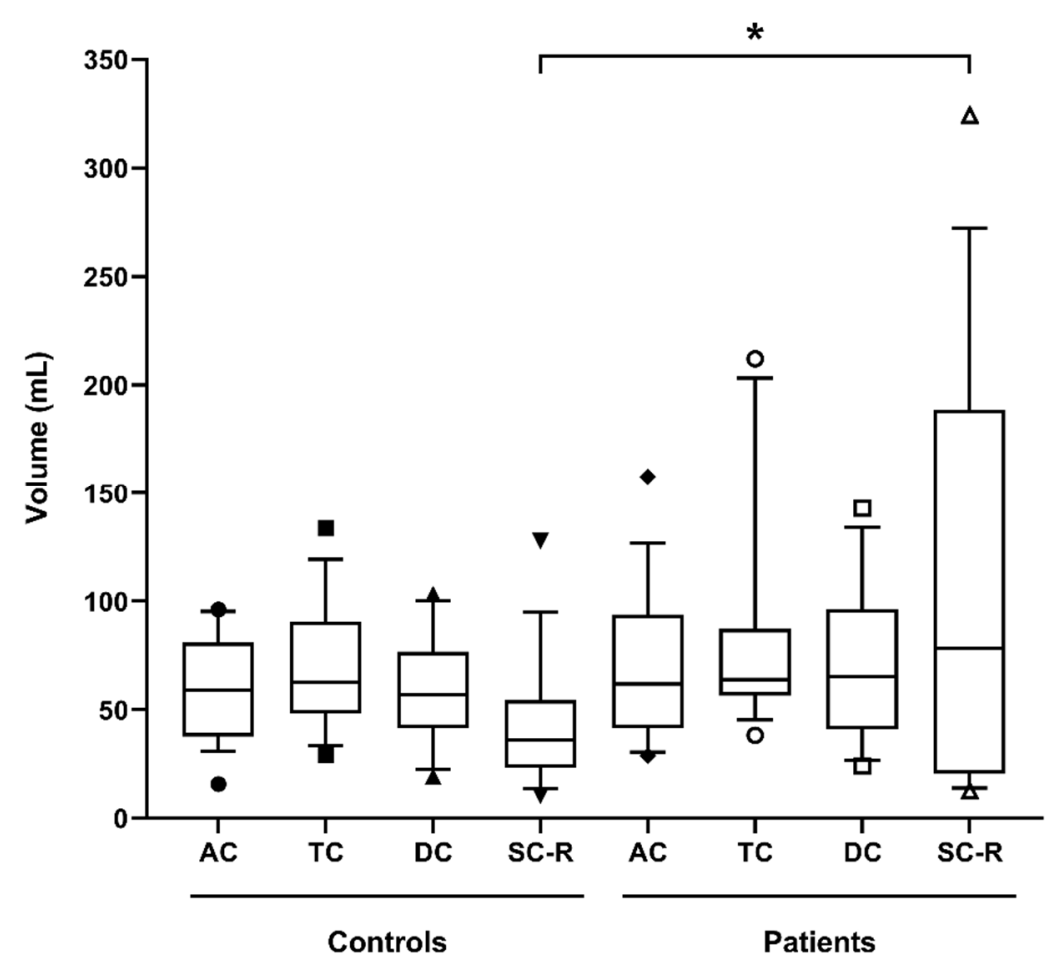

Figure 3. Regional colon volumes corrected for body surface area (ascending colon (AC), transverse colon (TC), descending colon (DC), sigmoid colon and rectum (SC-R)) for 19 controls and 16 patients with constipation. The box-and-whiskers plot shows the mean (+) and median (-) values of the regional ascending, transverse, descending, and sigmoid colon and rectum volumes. The box represents the 25 th -75 th centile, and the whiskers represent the 10th-90th centile ranges, respectively. * $p=0.0410$ one-tailed Mann-Whitney test.

Median and IQR data of the colon of controls and patients are summarised numerically in Table 1. 
Table 1. Regional and total colon volumes corrected for body surface area for ascending colon, transverse colon, descending colon, and sigmoid colon and rectum for $n=16$ patients with functional constipation and $n=19$ controls. The data are presented in median (interquartile range). $p$-values versus control are indicated in the last line of the table; $\mathrm{n} / \mathrm{s}=$ not significant.

\begin{tabular}{lccccc}
\hline & $\begin{array}{c}\text { Ascending } \\
\text { Colon }(\mathbf{m L})\end{array}$ & $\begin{array}{c}\text { Transverse } \\
\text { Colon }(\mathbf{m L})\end{array}$ & $\begin{array}{c}\text { Descending } \\
\text { Colon }(\mathbf{m L})\end{array}$ & $\begin{array}{c}\text { Sigmoid } \\
\text { Colon } \\
\text { and Rectum } \\
\mathbf{( m L )}\end{array}$ & $\begin{array}{c}\text { Total } \\
\text { Colon }(\mathbf{m L})\end{array}$ \\
\hline Controls & $59(38-81)$ & $63(48-91)$ & $57(41-77)$ & $36(23-54)$ & $227(180-263)$ \\
Patients & $62(41-94)$ & $64(56-87)$ & $65(41-96)$ & $78(20-189)$ & $309(243-384)$ \\
$p$-value & $\mathrm{n} / \mathrm{s}$ & $\mathrm{n} / \mathrm{s}$ & $\mathrm{n} / \mathrm{s}$ & $p<0.05$ & $p<0.001$ \\
\hline
\end{tabular}

There was a positive correlation between the total colonic volume and WGTT (Figure 4); coefficient of correlation $R=0.56, p=0.0005$.

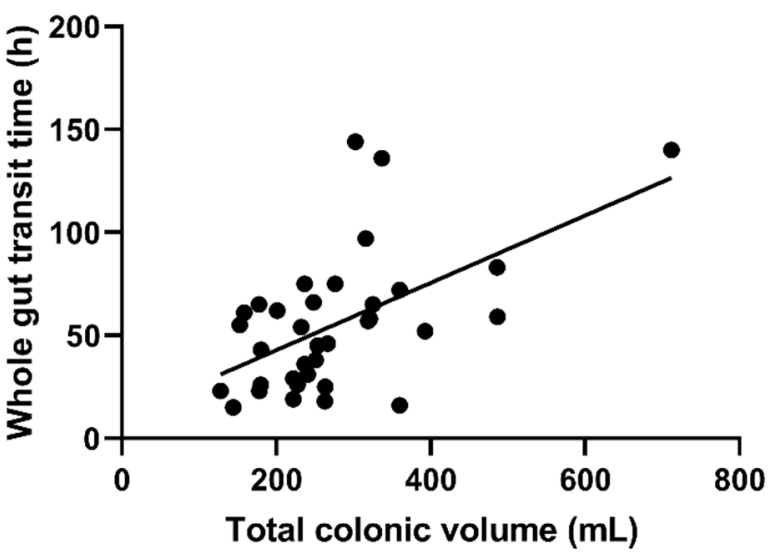

Figure 4. Correlation between whole gut transit time (WGTT) and total colonic volume, corrected for body surface area, for 19 controls and 16 patients with constipation coefficient of correlation $R=0.56$, $p=0.0005$.

\section{Discussion}

Colon volume has been shown to be increased in adult functional constipation (FC) $[20,21]$. This is the first comparative study on the undisturbed colonic volume in paediatric patients with FC and healthy paediatric controls using MRI. An early paper from 1973 investigated colonic volume in idiopathic constipation, but the volume was derived from invasive constant infusion studies on unphysiologically lavaged colons [28]. In that report, adult data were mixed with the data from the paediatric participants, making it difficult to compare.

In our study, the total colon volume was found to be larger in the paediatric patients with FC than in healthy controls. As expected, the data also showed some degree of correlation between colonic volume and height and between colonic volume and weight. These considerations led to the use of a common Mosteller correction for body surface area [27] to allow for a more realistic comparison between organ volumes, as previously reported for MRI colon volume in children and adults with cystic fibrosis [26].

We also found a moderate but significant correlation of transit with colonic volume. Intervention studies in healthy adults and adults with constipation showed that feeding bulking agents such as ispaghula [17] and kiwifruit [18] increased colonic volume, most obviously in the proximal colon, but these agents did not alter transit. Defecation has been shown to reduce colonic volume by around $1 / 3$, mostly after emptying the distal colon [22]. One can infer that defecation would influence the total colon volume of children with FC more, since the distal colon represents a bigger proportion of their total colon volume than in adults. For most adult subjects, colonic volume is determined by many 
factors other than whole gut transit time. In a recent, prospective MRI study in 20 adult patients with constipation, the maximum luminal colon diameter was measured from the images in different colonic segments [29]. The measurements were then correlated with gastrointestinal symptom rating scales. Interestingly, the authors reported several correlations of colonic diameters with symptom scores, including between the diameter of the descending colon and unsatisfactory defecation, and between the rectum and constipation scores. In our study, we did not collate symptom questionnaires on the MRI study day, and therefore any correlation between paediatric colon volumes and symptoms in our paediatric cohort remains to be investigated. Constipation can also be associated with changes in microbiota [30], so metabolic changes and influence on fermentation cannot be excluded. Limitations of this study included the post hoc analysis of images from a previous study [24], carried out unblinded and with a lack of correlation with clinical data, which the original feasibility study did not collect. This may increase the likelihood of chance findings, although the differences shown here had a high degree of statistical significance. Another limitation of this study was that, while the age ranges of the two groups were similar, the healthy participants were older.

These novel insights are also relevant for the pharmaceutical industry. Targeted drugdelivery systems are being investigated for their potential in treating colonic diseases directly through an intraluminal approach [31]. Increased knowledge of paediatric colonic volume will allow pharmacokinetic modelling parameters to be estimated more accurately, making drugs more bespoke to the recipient.

\section{Conclusions}

This study showed increased colon volumes in children with functional constipation compared to healthy controls. The volume increase in the patients was particularly marked in the sigmoid-rectum region. MRI allowed us to investigate colon volume in the paediatric population in a physiological state, without using any bowel preparation. Further work is needed to increase the number of participants studied and continue to investigate the relationship between colonic volume and WGTT. Increased knowledge of colonic abnormalities may improve understanding of this condition and help to direct treatment.

Author Contributions: Conceptualization, H.S. and L.M.; study conduct, H.S., N.A. and L.M.; patients identification and recruitment, S.K., S.L., M.P. and D.D.; methodology, H.S., P.A.G. and C.L.H.; formal analysis, H.S.; data interpretation, H.S., R.C.S., M.A.B., D.D. and L.M.; supervision: L.M. All authors contributed to the writing. All authors have read and agreed to the published version of the manuscript.

Funding: This work was funded by a National Institute for Health Research (NIHR) Invention for Innovation (i4i), award number II-LB-0814-20002. The views expressed are those of the authors and not necessarily those of the National Health Service (NHS), the NIHR, or the Department of Health \& Social Care. H.S. was funded by an academic scholarship from the Ministry of Health, Civil Service Commission, Kuwait.

Institutional Review Board Statement: The study was approved by the UK National Research Ethics Committee (17/WM/0049) and the UK Medicines and Healthcare Products Regulatory Agency (MHRA) (CI/2017/0054), and was registered on Clinicaltrials.gov (accessed on 1 January 2021) (NCT03564249).

Informed Consent Statement: Informed consent was obtained from all subjects involved in the study.

Data Availability Statement: The data presented in this study are available on request from the corresponding author. The data are not publicly available yet due to ongoing research work.

Conflicts of Interest: The authors declare no conflict of interest. The sponsors are public-funding bodies and had no role in the design, execution, interpretation, or writing of the study. 


\section{References}

1. Koppen, I.J.N.; Vriesman, M.H.; Saps, M.; Rajindrajith, S.; Shi, X.X.; van Etten-Jamaludin, F.S.; Di Lorenzo, C.; Benninga, M.A.; Tabbers, M.M. Prevalence of functional defecation disorders in children: A systematic review and meta-analysis. J. Pediatr. 2018, 198, 121-130. [CrossRef]

2. Athanasakos, E.P.; Kemal, K.I.; Malliwal, R.S.; Scott, S.M.; Williams, N.S.; Aziz, Q.; Ward, H.C.; Knowles, C.H. Clinical and psychosocial functioning in adolescents and young adults with anorectal malformations and chronic idiopathic constipation. Br. J. Surg. 2013, 100, 832-839. [CrossRef] [PubMed]

3. Hutson, J.M.; Catto-Smith, T.; Gibb, S.; Chase, J.; Shin, Y.M.; Stanton, M.; King, S.; Sutcliffe, J.; Ong, S.Y.; Djaja, S.; et al. Chronic constipation: No longer stuck! Characterization of colonic dysmotility as a new disorder in children. J. Pediatr. Surg. 2004, 39, 795-799. [CrossRef] [PubMed]

4. Hutson, J.M.; Chase, J.W.; Clarke, M.C.C.; King, S.K.; Sutcliffe, J.; Gibb, S.; Catto-Smith, A.G.; Robertson, V.J.; Southwell, B.R. Slow-transit constipation in children: Our experience. Pediatr. Surg. Int. 2009, 25, 403-406. [CrossRef] [PubMed]

5. Hyams, J.S.; Di Lorenzo, C.; Saps, M.; Shulman, R.J.; Staiano, A.; van Tilburg, M. Childhood functional gastrointestinal disorders: Child/adolescent. Gastroenterology 2016, 150, 1456-1468. [CrossRef]

6. Drossman, D.A. Functional gastrointestinal disorders: History, pathophysiology, clinical features, and rome iv. Gastroenterology 2016, 150, 1262-1279. [CrossRef]

7. Mirjalili, S.A.; Tarr, G.; Stringer, M.D. The length of the large intestine in children determined by computed tomography scan. Clin. Anat. 2017, 30, 887-893. [CrossRef]

8. Mahadevan, V. Anatomy of the rectum and anal canal. Surgery 2020, 38, 7-11. [CrossRef]

9. Underhill, B.M.L. Intestinal length in man. Br. Med. J. 1955, 2, 1243-1246. [CrossRef]

10. Hounnou, G.; Destrieux, C.; Desme, J.; Bertrand, P.; Velut, S. Anatomical study of the length of the human intestine. Surg. Radiol. Anat. 2002, 24, 290-294. [CrossRef]

11. Saunders, B.P.; Masaki, T.; Sawada, T.; Halligan, S.; Phillips, R.K.S.; Muto, T. A peroperative comparison of western and oriental colonic anatomy and mesenteric attachments. Int. J. Colorectal Dis. 1995, 10, 216-221. [CrossRef]

12. Sadahiro, S.; Ohmura, T.; Yamada, Y.; Saito, T.; Taki, Y. Analysis of length and surface area of each segment of the large intestine according to age, sex and physique. Surg. Radiol. Anat. 1992, 14, 251-257. [CrossRef]

13. Sharif, H.; Devadason, D.; Abrehart, N.; Stevenson, R.; Marciani, L. Imaging measurement of whole gut transit time in paediatric and adult functional gastrointestinal disorders: A systematic review and narrative synthesis. Diagnostics 2019, 9, 221. [CrossRef]

14. Orellana, B.; Monclus, E.; Brunet, P.; Navazo, I.; Bendezu, A.; Azpiroz, F. A scalable approach to T2-MRI colon segmentation. Med. Image Anal. 2020, 63. [CrossRef] [PubMed]

15. Nilsson, M.; Sandberg, T.H.; Poulsen, J.L.; Gram, M.; Frokjaer, J.B.; Ostergaard, L.R.; Krogh, K.; Brock, C.; Drewes, A.M. Quantification and variability in colonic volume with anovel magnetic resonance imaging method. Neurogastroenterol. Motil. 2015, 27, 1755-1763. [CrossRef] [PubMed]

16. Pritchard, S.E.; Marciani, L.; Garsed, K.C.; Hoad, C.L.; Thongborisute, W.; Roberts, E.; Gowland, P.A.; Spiller, R.C. Fasting and postprandial volumes of the undisturbed colon: Normal values and changes in diarrhea-predominant irritable bowel syndrome measured using serial MRI. Neurogastroenterol. Motil. 2014, 26, 124-130. [CrossRef]

17. Major, G.; Murray, K.; Singh, G.; Nowak, A.; Hoad, C.L.; Marciani, L.; Silos-Santiago, A.; Kurtz, C.B.; Johnston, J.M.; Gowland, P.; et al. Demonstration of differences in colonic volumes, transit, chyme consistency, and response to psyllium between healthy and constipated subjects using magnetic resonance imaging. Neurogastroenterol. Motil. 2018, 30, e13400. [CrossRef]

18. Wilkinson-Smith, V.; Dellschaft, N.; Ansell, J.; Hoad, C.; Marciani, L.; Gowland, P.; Spiller, R. Mechanisms underlying effects of kiwifruit on intestinal function shown by MRI in healthy volunteers. Aliment. Pharmacol. Ther. 2019, 49, 759-768. [CrossRef] [PubMed]

19. Marciani, L.; Garsed, K.C.; Hoad, C.L.; Fields, A.; Fordham, I.; Pritchard, S.E.; Placidi, E.; Murray, K.; Chaddock, G.; Costigan, C.; et al. Stimulation of colonic motility by oral PEG electrolyte bowel preparation assessed by MRI: Comparison of split vs single dose. Neurogastroenterol. Motil. 2014, 26, 1426-1436. [CrossRef] [PubMed]

20. Lam, C.; Chaddock, G.; Marciani, L.; Costigan, C.; Paul, J.; Cox, E.; Hoad, C.; Menys, A.; Pritchard, S.; Garsed, K.; et al. Colonic response to laxative ingestion as assessed by MRI differs in constipated irritable bowel syndrome compared to functional constipation. Neurogastroenterol. Motil. 2016, 28, 861-870. [CrossRef] [PubMed]

21. Lam, C.; Chaddock, G.; Marciani, L.; Costigan, C.; Cox, E.; Hoad, C.; Pritchard, S.; Gowland, P.; Spiller, R. Distinct abnormalities of small bowel and regional colonic volumes in subtypes of irritable bowel syndrome revealed by MRI. Am. J. Gastroenterol. 2017, 112, 346-355. [CrossRef]

22. Bendezu, R.A.; Mego, M.; Monclus, E.; Merino, X.; Accarino, A.; Malagelada, J.R.; Navazo, I.; Azpiroz, F. Colonic content: Effect of diet, meals, and defecation. Neurogastroenterol. Motil. 2017, 29, e12930. [CrossRef]

23. KeuzenkampJansen, C.W.; Fijnvandraat, C.J.; Kneepkens, C.M.F.; Douwes, A.C. Diagnostic dilemmas and results of treatment for chronic constipation. Arch. Dis. Child. 1996, 75, 36-41. [CrossRef] [PubMed]

24. Sharif, H.; Abrehart, N.; Hoad, C.L.; Murray, K.; Perkins, A.C.; Smith, M.; Gowland, P.A.; Spiller, R.C.; Harris, R.; Kirkham, S.; et al. Feasibility study of a new magnetic resonance imaging mini-capsule device to measure whole gut transit time in paediatric constipation. J. Pediatr. Gastroenterol. Nutr. 2020, 71, 604-611. [CrossRef] [PubMed] 
25. Eggers, H.; Brendel, B.; Duijndam, A.; Herigault, G. Dual-echo Dixon imaging with flexible choice of echo times. Magn. Reson. Med. 2011, 65, 96-107. [CrossRef] [PubMed]

26. Ng, C.; Dellschaft, N.S.; Hoad, C.L.; Marciani, L.; Ban, L.; Prayle, A.P.; Barr, H.L.; Jaudszus, A.; Mainz, J.G.; Spiller, R.C.; et al. Postprandial changes in gastrointestinal function and transit in cystic fibrosis assessed by Magnetic Resonance Imaging. J. Cyst. Fibros. 2021, in press.

27. El Edelbi, R.; Lindemalm, S.; Eksborg, S. Estimation of body surface area in various childhood ages-validation of the Mosteller formula. Acta Paediatr. 2012, 101, 540-544. [CrossRef]

28. Devroede, G.; Soffie, M. Colonic absorption in idiopathic constipation. Gastroenterology 1973, 64, 552-561. [CrossRef]

29. Inoh, Y.; Kanoshima, K.; Ohkuma, K.; Fuyuki, A.; Uchiyama, S.; Ohkubo, H.; Higurashi, T.; Iida, H.; Nonaka, T.; Fujita, K.; et al. Assessment of colonic contents in patients with chronic constipation using MRI. J. Clin. Biochem. Nutr. 2018, 62, 277-280. [CrossRef] [PubMed]

30. Parthasarathy, G.; Chen, J.; Chen, X.F.; Chia, N.; O'Connor, H.M.; Wolf, P.G.; Gaskins, H.R.; Bharucha, A.E. Relationship between microbiota of the colonic mucosa vs feces and symptoms, colonic transit, and methane production in female patients with chronic constipation. Gastroenterology 2016, 150, 367-379. [CrossRef]

31. Amidon, S.; Brown, J.E.; Dave, V.S. Colon-targeted oral drug delivery systems: Design trends and approaches. AAPS PharmSciTech 2015, 16, 731-741. [CrossRef] [PubMed] 